\title{
The Application of Similarity Theory and Dimensional Analysis to the Study of Centrifugal-Rotary Chopper of Forage Grain
}

\author{
Wacław Romaniuk ${ }^{1}$, Petr Savinykh ${ }^{2}$, Kinga Borek ${ }^{1}{ }^{(0}$, Kamil Roman $^{3, *}{ }^{(0)}$, Alexey Y. Isupov ${ }^{2}$, \\ Aleksandr Moshonkin ${ }^{2}$, Grzegorz Wałowski ${ }^{4}$ and Michał Roman ${ }^{5}$ (D) \\ 1 Institute of Technology and Life Sciences-National Research Institute, Department of Rural Technical \\ Infrastructure Systems, Warsaw Branch, Falenty, 3 Hrabska Avenue, 05-090 Raszyn, Poland; \\ w.romaniuk@itp.edu.pl (W.R.); k.borek@itp.edu.pl (K.B.) \\ 2 Federal Agrarian Scientific Center of the North-East Them. N.V. Rudnitsky, GNU NIISH-SH North-East \\ Scientific and Research Institute of Agriculture, 166a Lenin St., 610016 Kirov, Russia; \\ peter.savinykh@mail.ru (P.S.); mashin@yandex.ru (A.Y.I.); isupoff.aleks@yandex.ru (A.M.) \\ 3 Institute of Wood Sciences and Furniture, Warsaw University of Life Sciences, 166 Nowoursynowska St., \\ 02-787 Warsaw, Poland \\ 4 Institute of Technology and Life Sciences-National Research Institute, Department of Renewable Energies, \\ Branch in Poznan, Falenty, 3 Hrabska Avenue, 05-090 Raszyn, Poland; g.walowski@itp.edu.pl \\ 5 Institute of Economics and Finance, Warsaw University of Life Sciences, 166 Nowoursynowska St., \\ 02-787 Warsaw, Poland; michal_roman@sggw.edu.pl \\ * Correspondence: kamil_roman@sggw.edu.pl
}

check for updates

Citation: Romaniuk, W.; Savinykh, P.; Borek, K.; Roman, K.; Isupov, A.Y.; Moshonkin, A.; Wałowski, G.; Roman, M. The Application of Similarity Theory and Dimensional Analysis to the Study of Centrifugal-Rotary Chopper of Forage Grain. Energies 2021, 14, 4501. https://doi.org/ 10.3390/en14154501

Academic Editor: Hwai Chyuan Ong

Received: 26 May 2021

Accepted: 20 July 2021

Published: 26 July 2021

Publisher's Note: MDPI stays neutral with regard to jurisdictional claims in published maps and institutional affiliations.

Copyright: (c) 2021 by the authors. Licensee MDPI, Basel, Switzerland. This article is an open access article distributed under the terms and conditions of the Creative Commons Attribution (CC BY) license (https:// creativecommons.org/licenses/by/ $4.0 /)$.

\begin{abstract}
This article presents the device and the principle of operation of forage grain crushers that use the centrifugal force of inertia to supply the working bodies-which occurs as a result of rotation of the rotor with a vertical axis. The results of some tests of machines working on this principle have been characterized. Attention is drawn to the disadvantages of most research works, namely the lack of premises for creating shredders of this class with a wide range of performance. The aim of this work is to establish the relationship between the design and technological parameters for the operation of a centrifugal-rotary shredder using the theory of similarity and a dimensional analysis. Moreover, the experimental data show an empirical relationship when calculating the efficiency for the shredder model considered above. By applying the similarity criteria, dimensionless complexes were obtained, which allow to determine the significance of the parameters selected at the initial stage for the efficiency of the shredder. The novelty of this research is the application of the theory of similarity and the use of dimensional analysis, which allowed for scaling the results of the experimental data and obtaining a centrifugal-rotary shredder with higher efficiency, while maintaining the quality of the obtained product. This technique indicates the energy costs of the grinding process, which can be used to select the ratio of parameters in the shredder that would ensure that a minimum amount of energy is consumed.
\end{abstract}

Keywords: grain; hammer mill; shredder; disintegrator

\section{Introduction}

At least $50 \%$ of all grain produced in the world is used for the production of feed for farm animals. At the same time, the main goal is to obtain combined feeds. For example, their composition may consist of $(30 \div 80) \%$ of cereals and legumes or their derivatives obtained as a result of various processing (mechanical, thermal, pressure, etc.) [1-3].

The most popular and widely used component for combined feeds (mixtures) is the use of concentrated feeds obtained as a result of mechanical processing-grinding, which is primarily due to the simplicity and accessibility of this method. Moreover, in comparison with whole grain, subjecting grain to mechanical or thermal action increases its efficiency by up to $(10 \div 20) \%[1,2,4]$. 
Sergeev [4] obtained analytical dependences for calculating the performance of a centrifugal-rotary chopper, the required power, the number of cutting elements and radial channels on the ring protrusions (rows) of working bodies, depending on their design parameters and physical and mechanical properties of the material being crushed, allowing to develop choppers of various modifications. At the same time, in the proposed design of a centrifugal-rotary shredder, the optimal number of cutting elements on the first $Z_{1}=20$ and second $Z_{2}=30$ grinding pairs of ring protrusions of working bodies is justified, allowing to obtain a high-quality finished product with a dust-like fraction not exceeding $5 \%$, which is $5 \div 6$ times less than after grinding on hammer crushers. It has been established that two adjacent pairs of ring protrusions of working bodies are sufficient to obtain the zootechnically required quality of milling of feed grain and rapeseed; the rational cutting speed (chipping) of grain in a centrifugal-rotary chopper $v=(22 \div 46) \mathrm{m} / \mathrm{s}$.

In the work of Pushkareva [5], the technological process of grain destruction using working bodies with curved cutting elements in a centrifugal-rotary chopper is considered. Thus, it is theoretically and experimentally established that when moving along the walls of the through slots of the working bodies of the shredder, the grain is oriented with a long axis to the direction of exit. Due to this, it is cut into segments of a given size, which are deployed by the cut surface to the cutting plane at the second stage. Grinding of grains and their segments occurs mainly by the smallest cross-section. The rational use of cutting elements in the form of a cycloid with a forming circle of $4.81 \mathrm{~mm}$ is confirmed.

Druzhinin [6] claims that impact centrifugal shredders of feed grain are a new type of shredding equipment. They have a low specific energy consumption and a lower metal content than hammer crushers. Their introduction into production is hindered by the lack of methods for engineering calculation and design of these structures. He developed a mathematical model of the grain grinding process that allows you to determine the speed of grain movement along the vertical surface of the loading chamber of the shredder and the base of the knife tooth, which largely depends on the angular speed of the disks and the amount of movement of the grain. The analytical dependence of the shredder performance is also established, taking into account its design and operating parameters: the diameter of the receiving chamber, the speed of rotation of the disks, the length of the knife, their number and thickness, as well as the degree of filling of the inter-disk space and the properties of the crushed material.

Fomin [7] theoretically and experimentally established that by differentiating the cutting angle (grinding) of the material in accordance with the change in the coefficient of friction on the working bodies of the shredder during processing, it is possible to reduce the energy intensity of the process and improve the quality (reduce the amount of overground fraction) of the finished product. Fomin found that when moving the grain in a channel using a small-sized centrifugal-rotary-grinder, after the first ring, it is mostly cut into segments with a height of $(1 \div 2) \mathrm{mm}$, which are cut at the surface of the plane of the working body. Moreover, the cut (shear) segment of the weevil on the second and subsequent stages of crushing occurs primarily on the surface of pre-cut working bodies of the previous stage. A system of equations describing the translational and rotational motion of the crushed grain in the channel of the second and subsequent stages of the centrifugal-rotary shredder was also proposed.

The analysis of research works on centrifugal-rotary type grinders with a vertical axis of rotation has established that most of these works are aimed at achieving the goal of reducing the specific energy intensity of the process of grinding feed grain and increasing the uniformity of the granulometric composition of the finished product by improving the design and working bodies.

Thus, the problem of creating a size range of machines (shredders of the centrifugalrotary type) for farms with different needs for the productivity of machines for the production of concentrated feed remains [8-15]. This is due to the fact that simple scaling of existing working samples of shredders that provide low specific energy consumption and high quality of the resulting feed usually leads to an increase in the cost of construction 
and reduced performance. Thus, to preserve the results achieved, a new study with new samples is required. One of the methods for solving this problem is the application of the theory of physical similarity and dimensionality [10-13].

In agriculture, from a research point of view, there is increasingly more interest in centrifugal grain grinders. The principle of operation is to supply the crushed grain material to the working bodies with the help of inertia forces and then grind it, see Equations (1) and (2):

$$
\begin{aligned}
& Q_{i}=f\left(\omega_{e} ; P_{i} ; R_{i} ; t_{\mathrm{pe} 3}\right), \\
& Q_{c}=f\left(\omega_{e} ; P_{c} ; R_{c} ; \delta_{c}\right),
\end{aligned}
$$

This makes it possible to obtain lower energy costs in comparison with the widely distributed hammer crushers (Figure 1), which, in addition to the direct costs of destroying the grain, have energy costs for moving whole and crushed grain by means of air. In centrifugal or centrifugal-rotor grinders (Figure 2), the material is fed to the working bodies mainly due to the centrifugal force of inertia created by sliding the grain material along the rotating surface of the rotor with a vertically located axis of rotation and the parts installed on it that accelerate the crushed material and disintegrator (shock-centrifugal shredder) with intermediate separation in a centrifugal field (Figure 3).

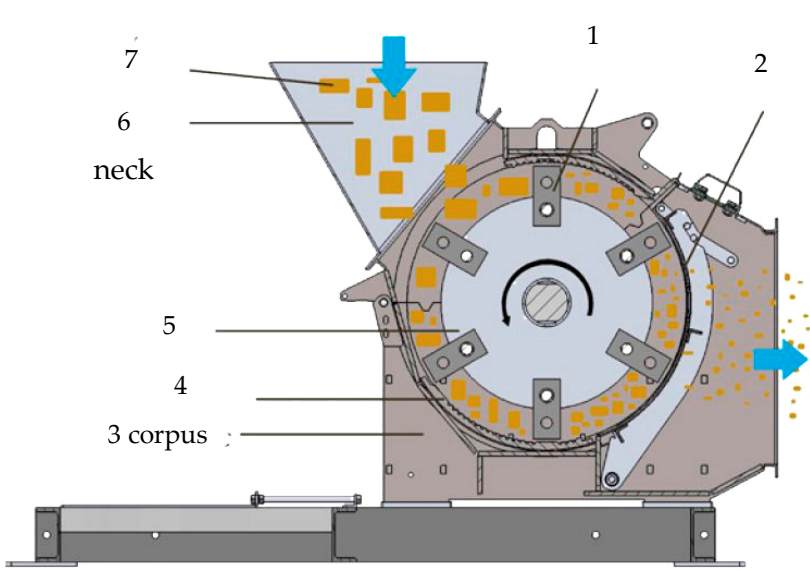

(a)

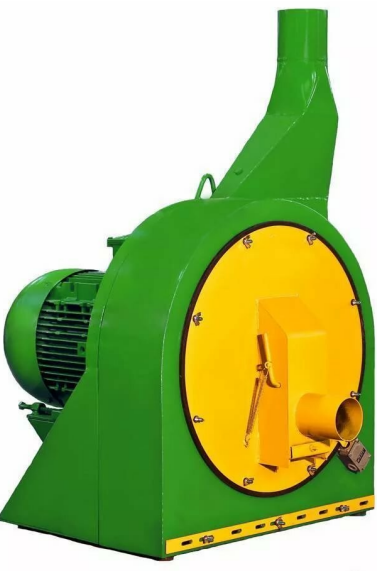

(b)

Figure 1. Grain hammer mill (own study): (a) section-view: 1-hammer, 2-sieve, 3-corpus, 4-deck, 5-rotor, 6-loading, 7-crushed raw materials; (b) housing-view.

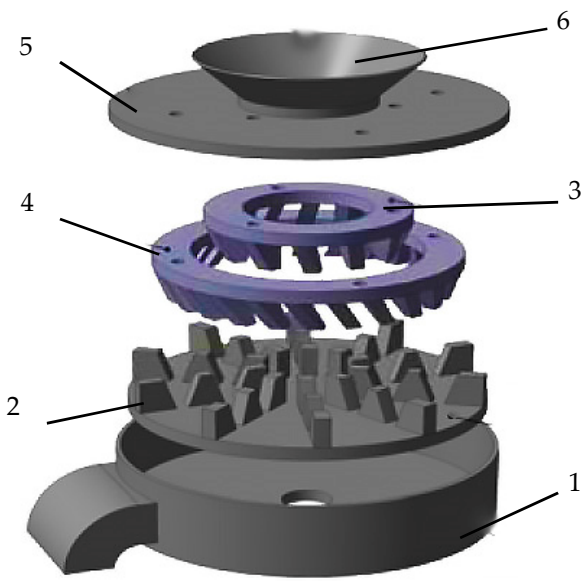

Figure 2. Grain shredder of centrifugal-rotary type with a knife working body (own study based on [4-6]): 1-housing; 2-lower disk-rotor; 3-ring of the first degree of grinding; 4-second-degree grinding ring; 5-cover; 6-receiving chamber. 


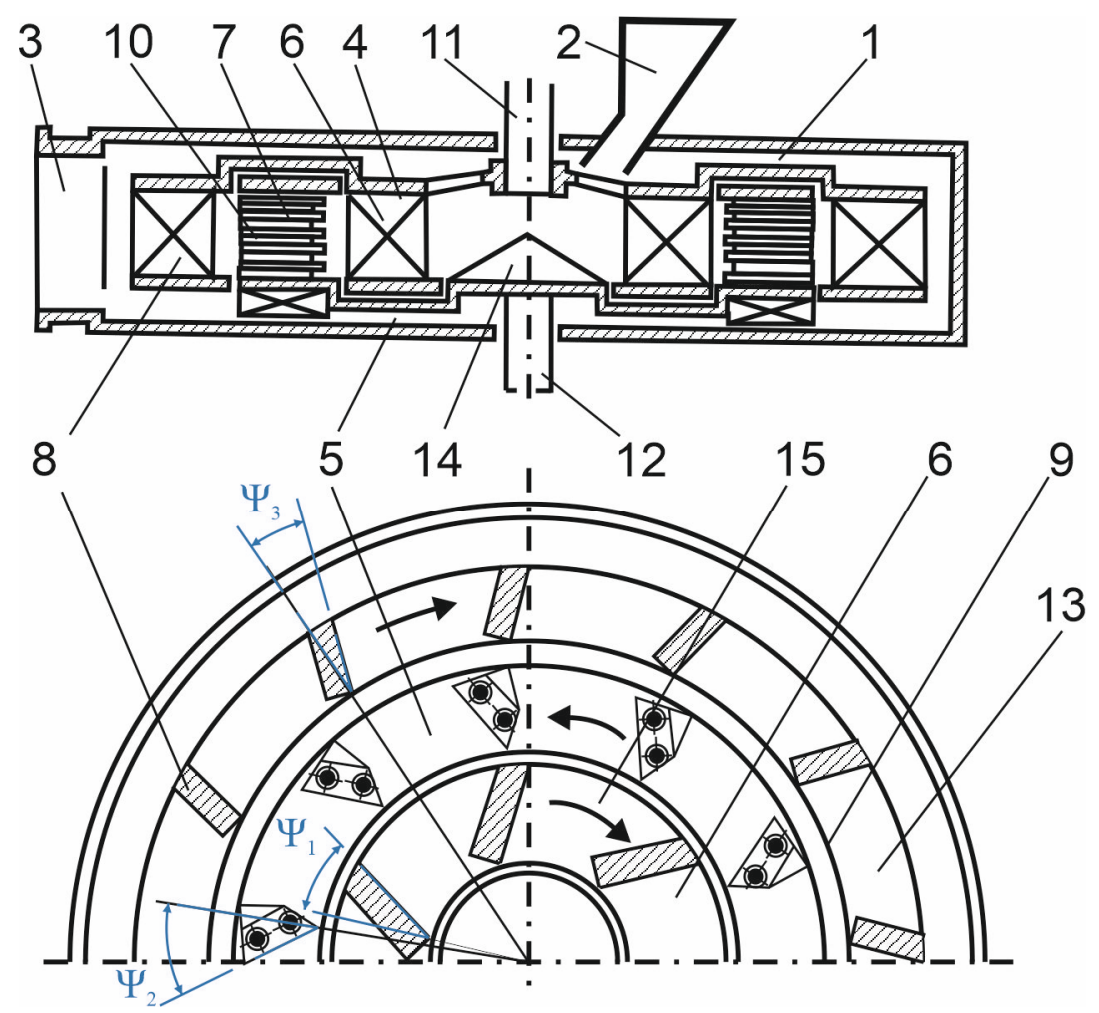

Figure 3. Disintegrator (shock-centrifugal shredder) with intermediate separation in a centrifugal field (own study based on [7]): 1-housing; 2-loading funnel; 3-exit hole; 4-the upper disc; 5-counter rotating disk; 6-flat element of the I-th row; 7-percussive elements of the intermediate row; 8-flat shock elements of the last row; 9-ring; 10-set of knives of the i-th row; 11-upper shaft; 12—lower shaft; 13—casing; 14—cone; 15—ower disk.

The theory of similarity and dimensional analysis are applied. The experiment was carried out in order to obtain the actual values of dimensionless coefficients and exponents in the derived empirical dependence applicable to the considered design of the rotary centrifugal grinder.

The aim of the presented research is to establish the relationship between the completed design and the technological parameters of the centrifugal-rotary work with the use of the theory of similarity and dimensional analysis. Moreover, after obtaining the empirical relationship, the efficiency for the presented model of the grinder will be calculated. This is to obtain a shredder with higher efficiency while maintaining the quality of the product obtained.

\section{Materials and Methods}

Any experimental study, even of machines as simple in design and operation as a hammer mill and a centrifugal shredder, requires a large and labor-intensive effort from the experimental researcher to implement the methods of single- and multi-factor experiments. Therefore, to reduce the volume of work performed without reducing its quality, the theory of physical similarity and dimension analysis will be widely introduced into research work.

This analysis allows you to solve problems of generalizing the results of experiments, to select universal coordinates when solving problems of numerical or analytical experiment, while it is also one of the main methods for reducing the number of factors under study when planning an experiment [10-12].

The analysis is based on the doctrine of similar processes (phenomena) in nature and technology. Similar processes occur under similar geometric and temporal conditions, have the same physical nature, and are described by the same equations in form and substance. Their mathematical models are similar to real processes and objects (more 
precisely, the models of their state or functioning), which are a system of mathematical relations describing the relationships between parameters, or functional dependencies between them under specified conditions, which determine the values of these parameters as a result of calculation [10-12].

The foundations of the modern similarity theory and dimension analysis are laid out by the lots of works of Rayleigh, Buckingham, and Bridgman, in which it is essential to establish a connection between the maximum possible number of dimensionless complexes and the number of dimensional quantities from which they are composed-the $\pi$ theorems:

Let there exista physical law, expressed in the form based on some dimension, generally speaking, the values of the dimensional governing parameters the same. This dependence can be represented as a dependence of a dimensionless quantity on dimensionless combinations of defining parameters. The number of these dimensionless combinations is less than the total number of dimensional defining parameters by the number of defining parameters with independent dimension.

Replacing a real physical system with a model that is based on so-called similarity laws allows you to transfer data obtained from the model to the original physical system. It is clear that no model can fully correspond to the described object, and the task of the researcher is to choose a reasonable compromise between the accuracy of the model, for which it has to be complicated, and the simplicity of calculating the desired parameters or functions. With the advent of computers, it became possible to significantly complicate the models used and obtain fairly reliable results, thereby replacing a physical experiment on a machine or stand with a mathematical one. Of course, computational research using mathematical models can never completely replace experimental research of real objects. These studies remain necessary for selective assessment of the accuracy of mathematical models, for obtaining or refining the initial parameters, as well as the empirical and semi-empirical dependencies laid in them [10-12].

\subsection{Experimental Stand}

As an example, let us consider a centrifugal-rotary shredder of feed grain [14-18] with a knife working body (Figure $4 \mathrm{a}$ ). The device for crushing bulk materials consists of a fixed housing (1) with loading (2) and output (3) pipes. Inside the case, two rotating adjacent disks are installed coaxially: the upper (4) and lower (5). On the working surface of the lower disc (5), annular projections are made (6), and the working surface of the upper disk (4) is installed, i.e., the blades (7) (Figure 4b), which have a diamond shape with small sharpening angles and relatively large diagonals. Moreover, the outer row of knives (8) forms a separation surface; the angle changes, which allows to steplessly adjust the degree of grinding material. The lower disk (5) has radial through grooves (9), made at an angle in the direction opposite to the direction of rotation of this disk (Figure 4c). The lower disk (5) is mounted on the flange of the drive shaft (10) and is rotated by means of a pulley (11) that is mounted on top of it. The upper disk (4) is rigidly attached to the fixed body (1). In the upper part of the fixed housing, a receiving chamber (12) is installed, which is formed by vertical walls. The receiving chamber (12) in the upper part is connected to the loading pipe (2) and is connected by means of the radial windows (13) to the working chamber (14), which is the space between disks 4 and 5 .

The chopper is as follows: the sample is exposed to the first cutting pair, moves under the action of centrifugal force through the grooves to the next pairs, and then reaches the outer row of blades (8), which form the separating surface, and is held in the gap between the blades (8) and is influenced by the air flow created by the rotating bottom disk (5) out of the housing (1) through the outlet (3). 
(a)

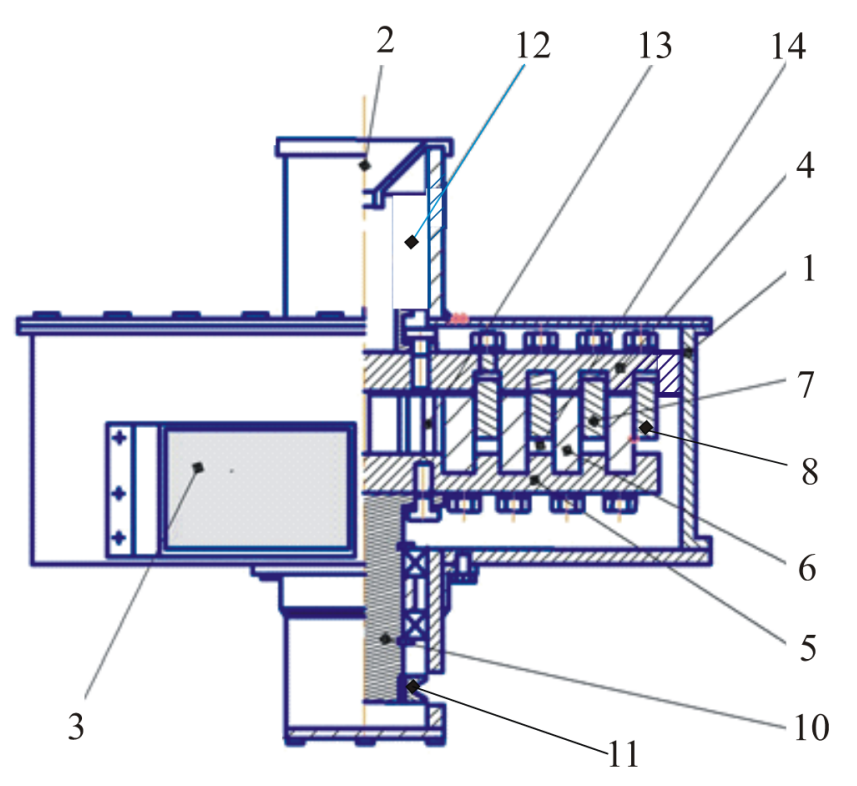

(b)

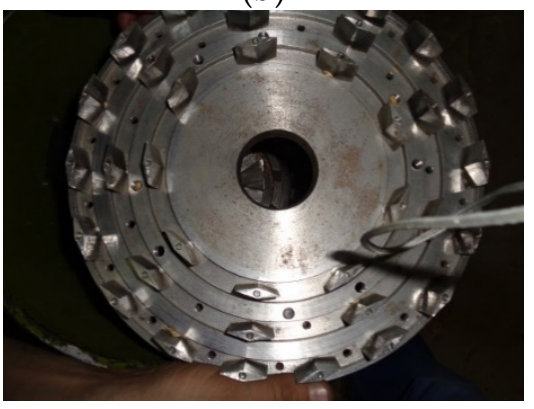

(c)

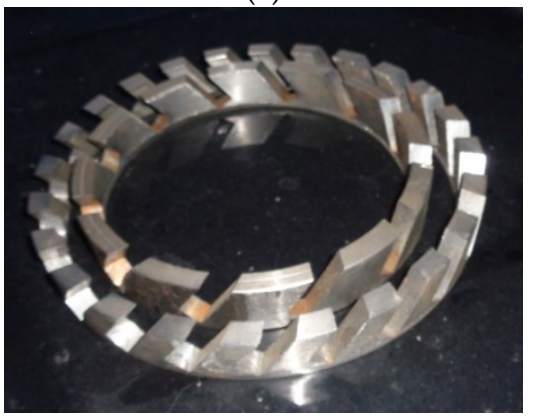

Figure 4. Design and technological scheme of a rotary-centrifugal type grain shredder (a): 1—housing, 2-loading pipe, 3-output pipes, 4-upper disks, 5-lower disks, 6-projections of the lower disk, 7-blades of the upper disk, 8-outer row knives, 9-grooves of the lower disk, 10-drive shaft, 11-pulley, 12-receiving chamber, 13-radial windows, 14-working chamber, rings with countersinks (b) and a lower disk with knives (c) (own study).

\subsection{Scope and Research Mehodology}

This work is aimed at establishing the relationship between the design and technological parameters for the performance of a centrifugal-rotary chopper using similarity theory and dimension analysis. Additionally, with the results of experimental data, we can get an empirical dependence to calculate the performance for the above model of the shredder.

\section{Results and Discussion}

Having information about the influence of various factors on the operation of the centrifugal-rotary shredder $[1-7,9,14-17,19-23]$, we consider them as a set of criteria that affect the performance during the grinding and separation process. In this case, the performance during the grinding process will be considered at each degree of grinding separately, see Equations (1) and (2).

A number of parameters were not considered because of their occurrence in view of the parameters of Equations (1) and (2). This includes in our case the number and width of knives, as they are included in the formula to calculate the time (period) of the cutting at an appropriate degree of decomposition, see Equation (3). Additionally, given the fact that the blades forming the separating surface is set with overlap, the time separation $t_{c}$, the number of knives installed on the stage of separation $n_{c}$, the installation angle $\alpha$ of blades and their width $B_{c}$ were discarded because they define the gap between the blades $\delta_{c}$.

$$
t_{i . \mathrm{pe} 3}=t_{i . \mathrm{o}}-t_{i . \mathrm{xx}}=\frac{2 \pi R_{i}-B_{i} n_{i}}{\omega_{e} R_{i}},
$$

Since the number of physical parameters for the grinding stage $N_{i}$ and separation $N_{\mathcal{C}}$ is five, and the number of units with independent or primary dimensions is three, i.e., mass, $\mathrm{kg}$; length, $\mathrm{m}$; and time, $\mathrm{s}$, their difference is greater than one. Thus, the procedure for finding similarity criteria leads to multi-valued results. 
The desired values can be represented as in Equations (4) and (5):

$$
\begin{gathered}
Q_{i}=C_{i} \cdot \omega_{e}^{x_{1}} \cdot P_{i}^{x_{2}} \cdot R_{i}^{x_{3}} \cdot t_{i . \mathrm{pe} 3}{ }^{x_{4}} \\
Q_{c}=C_{c} \cdot \omega_{e}^{x_{5}} \cdot P_{c}^{x_{6}} \cdot R_{c}^{x_{7}} \cdot \delta_{c}^{x_{8}}
\end{gathered}
$$

Substitute the dimensions of the corresponding quantities in Equations (6) and (7):

$$
\begin{gathered}
\left(\frac{\mathrm{kg}}{\mathrm{s}}\right)=C_{i} \cdot\left(\mathrm{s}^{-1}\right)^{x_{1}} \cdot\left(\frac{\mathrm{kg}}{\mathrm{s}}\right)^{x_{2}} \cdot m^{x_{3}} \cdot(s)^{x_{4}} . \\
\left(\frac{\mathrm{kg}}{\mathrm{s}}\right)=C_{c} \cdot\left(\mathrm{s}^{-1}\right)^{x_{5}} \cdot\left(\frac{\mathrm{kg}}{\mathrm{s}}\right)^{x_{6}} \cdot(m)^{x_{7}} \cdot(m)^{x_{8}} .
\end{gathered}
$$

From the similarity theory and dimension analysis, it follows that the left and right sides of Equations (6) and (7) must have the same dimension. By summing the exponents for the same units of measurement, we get Equations (8) and (9):

$$
\begin{array}{ll}
{[\mathrm{kg}]:} & \left\{\begin{array}{c}
1=x_{2} \\
0=x_{3}
\end{array}\right. \\
{[\mathrm{m}]:} & \left\{\begin{array}{c}
x_{1}-x_{2}+x_{4} . \\
1=x_{6}
\end{array}\right. \\
{[\mathrm{kg}]:} & \quad\left\{\begin{array}{c}
1=x_{7}+x_{8} \\
0=-x_{5}-x_{6} . \\
{[\mathrm{m}]:}
\end{array}\right.
\end{array}
$$

The solution of the obtained system of algebraic equations gives the values and dependencies between exponents $x_{j}$ shown in Equations (10) and (11):

$$
\begin{gathered}
x_{2}=1, \quad x_{1}=x_{4}, \quad x_{3}=0 . \\
x_{6}=1, \quad x_{7}=-x_{8}, \quad x_{5}=0 .
\end{gathered}
$$

Substituting the obtained exponents of degrees in Equations (10) and (11) in Equations (6) and (7), we obtain Equations (12) and (13):

$$
\begin{aligned}
& Q_{i}=C_{i} \cdot \omega_{e}{ }^{x_{1}} \cdot P_{i}^{1} \cdot R_{i}{ }^{0} \cdot t_{i . \mathrm{pe} 3}{ }^{x_{1}} . \\
& Q_{c}=C_{c} \cdot \omega_{e}^{x_{5}} \cdot P_{c}^{x_{6}} \cdot R_{c}{ }^{x_{7}} \cdot \delta_{c}^{x_{8}}
\end{aligned}
$$

Let us rewrite these equations and present them in the form of Equations (14) and (15):

$$
\frac{Q_{i}}{P_{i}}=C_{i} \cdot\left(\omega_{e} t_{i \cdot \mathrm{pe} 3}\right)^{x_{1}}
$$

The dimensionless complexes included in Equations (14) and (15) represent the required similarity criteria:

- Dimensionless ratio that characterizes the ratio of the output to the incoming grain material for grinding, Equation (14a):

$$
Q_{i} / P_{i}=\bar{\eta}_{i}
$$

- Dimensionless criterion that determines the angle at which the grain material moves non-stop at the selected knife installation radius, Equation (14b):

$$
\begin{array}{r}
\omega_{e} t_{i . \mathrm{pe} 3}=\bar{\varphi}_{i} \\
\frac{Q_{c}}{P_{c}}=C_{c} \cdot\left(\frac{\delta_{c}}{R_{c}}\right)^{x_{8}}
\end{array}
$$


- Dimensionless ratio describing the ratio of the output to the separation of the crushed grain material, Equation (15a):

$$
Q_{c} / P_{c}=\bar{\eta}_{c}
$$

- Dimensionless geometric criterion, Equation (15b):

$$
\delta_{c} / R_{c}=\bar{R}
$$

The expressions that characterize the grinding and separation in the considered centrifugal-rotary shredder of feed grain can be written as in Equations (16) and (17):

$$
\begin{aligned}
& \bar{\eta}_{i}=C_{i} \cdot \bar{\varphi}_{i}{ }^{a_{i}} . \\
& \bar{\eta}_{c}=C_{c} \cdot \bar{R}^{b} .
\end{aligned}
$$

The values of constant coefficients $C_{i}$ and $C_{c}$, as well as indicators of degrees $a_{i}$ and $b$, are determined by the results of an experimental study of the grinding and separation process. However, obtaining these data will require quite "voluminous" experimental studies. Therefore, applying the Formulas (14) and (13) to the considered design of a centrifugal-rotary feed grain shredder, we obtain Equation (18):

$$
Q_{c}=C \cdot C_{1} \cdot C_{2} \cdot P_{1} \cdot\left(\omega_{e} \cdot t_{2 \cdot \mathrm{pe} 3}\right)^{x_{9}} \cdot\left(\omega_{e} \cdot t_{1 . \mathrm{pe} 3}\right)^{x_{1}} \cdot\left(\delta_{c} / R_{c}\right)^{x_{8}}
$$

Substituting Equation (3) in Equation (18), we get:

$$
Q_{c}=C_{0} \cdot P_{1} \cdot\left(\frac{2 \pi R_{2}-B_{2} n_{2}}{R_{2}}\right)^{x_{9}} \cdot\left(\frac{2 \pi R_{1}-B_{1} n_{1}}{R_{1}}\right)^{x_{1}} \cdot\left(\frac{\delta_{c}}{R}\right)^{x_{8}}
$$

or Equation (20):

$$
\bar{\eta}=C_{0} \cdot \bar{\varphi}_{2}{ }^{a_{2}} \cdot \bar{\varphi}_{1}{ }^{a_{1}} \cdot \bar{R}^{b}
$$

where $C_{0}=C \cdot C_{1} \cdot C_{2}$ is the final dimensionless coefficient.

To calculate the values of the constant coefficient $C_{0}$ and the exponents $x_{1}, x_{8}$ and $x_{9}$ in Equation (19), we will use the results when implementing the planning methodology for a multi-factor experiment $[21,22]$. Thus, during the experimental work, the second-order Box-Benkin composite plan was used for four factors: the rotation frequency $N$, the feed of grain material $P$, the gap of the separating surface $\delta$, and the number of knives at the second stage of grinding $n_{2}$. The number of knives at the first stage of grinding $\left(n_{1}=3\right)$, knife mounting diameters $\left(D_{1}=0.085 \mathrm{~m}, D_{2}=0.105 \mathrm{~m}, D_{3}=0.129 \mathrm{~m}\right)$, and knife width $(B=0.056 \mathrm{~m})$ were taken based on the results of our previous preliminary studies [13-16] and the published results of other researchers $[4-9,19]$. The matrix of the plan with the results of the experiment is shown in Table 1.

The experiment results were processed using the Statgraphics software package. After excluding ineffective factors and their interactions, adjusted ANOVA [24] variance analysis data were obtained-see Table 2.

To analyze the influence of variable factors on the performance of the centrifugalrotary chopper, the design under consideration, we have constructed graphs of the response surfaces, one of which is shown in Figure 5.

To calculate the values of the constant coefficient $C_{0}$ and the exponents $x_{1}, x_{8}$ and $x_{9}$ in Equation (19), we will compose and solve a system of equations consisting of data from Table $1[10,11]$. 
Table 1. Variable values of parameters and productivity of the centrifugal-rotary feed grain shredder.

\begin{tabular}{|c|c|c|c|c|c|}
\hline No. & $\begin{array}{c}p, \\
\mathrm{~kg} / \mathrm{s}\end{array}$ & $\begin{array}{c}\omega, \\
\min ^{-1}\end{array}$ & $\begin{array}{c}\delta_{c r} \\
\mathbf{m m}\end{array}$ & $\begin{array}{l}n_{2} \\
\text { pcs }\end{array}$ & $\underset{\mathrm{kg} / \mathrm{min}}{Q}$ \\
\hline 1 & 0.038167 & 900 & 2.5 & 12 & 0.0362 \\
\hline 2 & 0.022667 & 1200 & 2.5 & 12 & 0.014783 \\
\hline 3 & 0.038167 & 900 & 2.5 & 12 & 0.0362 \\
\hline 4 & 0.038167 & 1200 & 2.5 & 18 & 0.022917 \\
\hline 5 & 0.022667 & 900 & 1.6 & 12 & 0.015133 \\
\hline 6 & 0.038167 & 1200 & 2.5 & 9 & 0.013367 \\
\hline 7 & 0.0505 & 900 & 2.5 & 18 & 0.0272 \\
\hline 8 & 0.038167 & 900 & 1.6 & 9 & 0.03635 \\
\hline 9 & 0.022667 & 900 & 2.5 & 18 & 0.015 \\
\hline 10 & 0.038167 & 1200 & 1.6 & 12 & 0.024 \\
\hline 11 & 0.038167 & 900 & 3.2 & 9 & 0.028317 \\
\hline 12 & 0.038167 & 600 & 3.2 & 12 & 0.02595 \\
\hline 13 & 0.038167 & 900 & 2.5 & 12 & 0.0362 \\
\hline 14 & 0.038167 & 600 & 2.5 & 18 & 0.019233 \\
\hline 15 & 0.022667 & 600 & 2.5 & 12 & 0.01145 \\
\hline 16 & 0.0505 & 900 & 3.2 & 12 & 0.05095 \\
\hline 17 & 0.0505 & 1200 & 2.5 & 12 & 0.015183 \\
\hline 18 & 0.038167 & 900 & 3.2 & 18 & 0.020133 \\
\hline 19 & 0.0505 & 900 & 1.6 & 12 & 0.025667 \\
\hline 20 & 0.0505 & 600 & 2.5 & 12 & 0.014167 \\
\hline 21 & 0.038167 & 600 & 1.6 & 12 & 0.0211 \\
\hline 22 & 0.0505 & 900 & 2.5 & 9 & 0.02725 \\
\hline 23 & 0.038167 & 600 & 3.2 & 12 & 0.0288 \\
\hline 24 & 0.038167 & 600 & 2.5 & 9 & 0.0204 \\
\hline 25 & 0.022667 & 900 & 3.2 & 12 & 0.014333 \\
\hline 26 & 0.038167 & 900 & 1.6 & 18 & 0.01685 \\
\hline 27 & 0.022667 & 900 & 2.5 & 9 & 0.014133 \\
\hline
\end{tabular}

Table 2. ANOVA variance analysis Data.

\begin{tabular}{ccccccc}
\hline Transformation & Model d.f. & $p$-Value & Error d.f. & $\begin{array}{c}\text { Stnd. } \\
\text { Error }\end{array}$ & R-Squared & $\begin{array}{c}\text { Adj. } \\
\text { R-Squared }\end{array}$ \\
\hline 5 & 0.0001 & 21 & 0.3642 & 67.43 & 59.68 \\
\hline
\end{tabular}

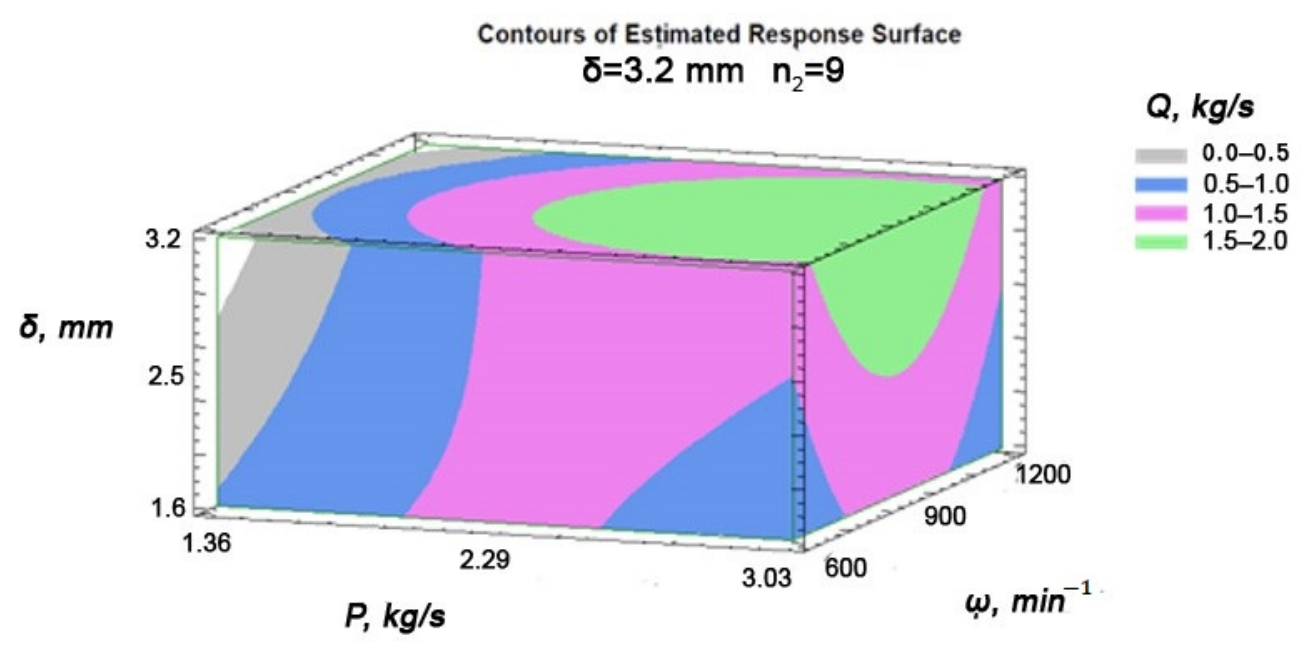

Figure 5. Three-dimensional graph of the response surfaces of the performance of the shredder $Q$ at a fixed value of the number of knives at the second stage $\left(n_{2}=9\right)$ (own study). 
The resulting system was solved numerically using Matcad Prime engineering mathematical software with an initial approximation, see Equation $(21 a, b)$ :

$$
\begin{gathered}
C_{0}=x_{1}=x_{8}=x_{9}=0 \\
\left\{\begin{array}{c}
C_{0}=2062 \\
x_{1}=3.85 \cdot 10^{-9} \sim 0 \\
x_{8}=0.612 \\
x_{9}=0.317
\end{array}\right.
\end{gathered}
$$

By substituting Equation (21a,b) in Equation (19), we finally get Equation (22):

$$
Q_{c}=2.062 \cdot P_{1} \cdot\left(\frac{2 \pi R_{2}-B_{2} n_{2}}{R_{2}}\right)^{0.317} \cdot\left(\frac{\delta_{c}}{R_{c}}\right)^{0.612}
$$

The relative error of the calculated data from the experimental data varied from $10^{-9}$ to $10^{-5} \%$, except for the second row in Table 2 , where the error was $45 \%$. This is due to the measurement error in obtaining experimental data and is confirmed by the data of dispersion analysis—see Table 1.

The article describes the device and the principle of operation of forage grain crushers that use the centrifugal force of inertia to supply the working bodies, which is formed as a result of the rotation of the rotor with a vertical axis. The drawback of most research projects is that there are no reasons to create shredders of this class with a wide range of performance [25]. An example of a construction is given and the principle of operation of a grinding machine with a centrifugal impeller is described. Based on the analysis of the presented construction of the grinder, mathematical modeling was carried out in order to obtain the dependence of the impact of constructional and technological parameters on productivity. Dimensionless coefficients of the derived empirical regularity have been established experimentally.

\section{Conclusions}

(1) The use of similarity theory and dimension analysis allowed us to obtain an empirical dependence for calculating the performance of a centrifugal-rotary grain shredder of the considered design. Thus, this method makes it possible to solve the problem of establishing the relationship between different parameters with a minimum amount of experimental work with sufficient confidence. Therefore, at the next stage of our research work, we should consider a more complex problem-the relationship of energy costs in a centrifugal-rotor type chopper with a knife working body. Thus, in this case, the shape and sharpness of the blade of knives and counter-cuts, the size of the grain material coming to the grinding, its radial and circumferential speed, the degree of grinding, the angle of installation of knives, and other parameters will be of great importance to those already considered earlier (1);

(2) Using similarity criteria, dimensionless complexes were obtained that allow us to determine the importance of the parameters selected at the initial stage on the performance of the shredder;

(3) The use of similarity theory and dimension analysis will allow you to scale the results of experimental data and get a centrifugal-rotary type chopper with greater productivity while maintaining the quality of the resulting product. Moreover, this technique can be used to determine the energy costs of the grinding process, which can used to choose the ratio of parameters in the shredder that would ensure a minimum amount of energy is consumed.

(4) The chopper can also be used to prepare biomass by shredding the residues [26]. In that way, prepared substrate can be used in the methane fermentation process, which improves the efficiency of the process. 
Author Contributions: Conceptualization, W.R. and P.S.; methodology, P.S., A.Y.I., A.M. and K.R.; software, K.R. and M.R.; validation, W.R., P.S., K.B., K.R., A.Y.I., A.M. and M.R.; formal analysis, P.S., W.R., K.R., M.R. and A.M.; investigation, A.Y.I., W.R., K.R., M.R., and P.S.; resources, P.S., A.Y.I. and A.M.; data curation, K.R.; writing—original draft preparation, P.S., A.Y.I., G.W. and A.M.; writing-review and editing, K.B., G.W. and K.R.; visualization, P.S., G.W., W.R., K.R., M.R. and A.Y.I.; supervision, W.R.; project administration, K.B., W.R., K.R., M.R. and P.S.; funding acquisition, M.R. and K.R. All authors have read and agreed to the published version of the manuscript.

Funding: This research received no external funding.

Institutional Review Board Statement: Not applicable.

Informed Consent Statement: Not applicable.

Data Availability Statement: Not applicable.

Acknowledgments: The work was carried out in accordance with the theme of research work 05282019-0094 "Creation of innovative technologies and technical means of a new generation for the mechanization of crop production and livestock, adapted to the specific climatic conditions of the North-East of the European part of Russia" for 2019-2023 under section 10.9, subsection 162 of the FNI Program of the state academies of Sciences for 2013-2020.

Conflicts of Interest: The authors declare no conflict of interest.

\section{Symbols}

$B_{i}$

$C_{i}, C_{c}$

$P_{c}$

$P_{i}$

$P_{1}$

$Q_{c}$

$Q_{i}$

$R_{c}$

$R_{i}$

$t_{i . \mathrm{o}}$

$t_{i . \mathrm{pe} 3}$

$s t_{i . \mathrm{xx}}$

$n_{i}$

$x_{1}, x_{2}, \ldots, x_{8}, \ldots, x_{j}$

$x_{9}$

$\delta_{c}$

$\bar{\eta}$

$\omega_{e}$ half the width of the knife constant dimensionless coefficients

the flow of the grain material for the separation

feed of grain material to the $i$-stage of grinding

feed of grain material to the first stage of grinding, which can be assumed to be equal to the feed from the storage hopper $P_{0}$

productivity of the centrifugal-rotary type shredder on separation

productivity of the centrifugal-rotary type shredder at the $i$-stage of grinding

radius of installation of knives forming a separating surface

radius of installation of knives at the $i$-stage of grinding

time (period) of one revolution

time (period) of cutting at the $i$-stage of grinding

time (period) of idling or stopping the movement of grain material as a result of overlapping

the channel with the knife surface

the number of installed blades

exponent

degree indicator for the second stage of grinding

the gap between the knives forming the separating surface

dimensionless ratio characterizing the loss in productivity of the grain material shredder angular speed of rotation of the rotor $\mathrm{m}$

$\mathrm{kg} \cdot \mathrm{s}^{-1}$

$\mathrm{kg} \cdot \mathrm{s}^{-1}$

$\mathrm{kg} \cdot \mathrm{s}^{-1}$

$\mathrm{kg} \cdot \mathrm{s}^{-1}$

$\mathrm{kg} \cdot \mathrm{s}^{-1}$

$\mathrm{m}$

$\mathrm{m}$

$\mathrm{s}$

$\mathrm{s}$

$\mathrm{s}$

PCs

$\mathrm{m}$

$\mathrm{s}^{-1}$

\section{References}

1. Melnikov, S.V.; Vagin, B.I.; Andreev, P.A. Mechanization of Livestock Farms; Kolos: Moscow, Russia, $1969 ;$ p. 440.

2. Sysuev, V.A.; Aleshkin, A.V.; Savinykh, P.A. Forage Preparation machines. In Theory, Development, Experiment; North-Eastern Zonal Agricultural Research\&Development Institute: Kirov, Russia, 2008; Volume I, p. 640.

3. Patro, M.; Zubala, T. Use of different form of retention as the condition of sustainable management of water resources in rural environment. J. Water Land Dev. 2020, 126-135. [CrossRef]

4. Sergeev, N.S. Centrifugal-Rotary Feed Grain Grinders. Ph.D. Thesis, Technical Sciences, Chelyabinsk, Russia, 2008 ; p. 315.

5. Pushkarev, A.S. Improving the Efficiency of the Grain Milling Process by Using Working Bodies with Cutting Elements of Curved Shape. Ph.D. Thesis, Cand. Technical Sciences, Barnaul, Russia, 2018; p. 22.

6. Druzhinin, R.A. Improving the Working Process of a Shock-Centrifugal Chopper. Ph.D. Thesis, Voronezh State Technical University, Voronezh, Russia, 2014; p. 169.

7. Fomin, V.V. Reducing Energy Consumption and Increasing the Uniformity of Grain Grinding in A Small-Sized Centrifugal-Rotary Shredder. Ph.D. Thesis, Author's Abstract, Cand. Technical Sciences, Novosibirsk, Russia, 2010; p. 23. 
8. Soloviy, C.; Malovanyy, M.; Nykyforov, V.; Dihtyar, S. Critical analysis of biotechnologies on using resource potential of hydrobionts. J. Water Land Dev. 2020, 143-150. [CrossRef]

9. Turubanov, N.V.; Medvedev, O.Y.; Isupov, A.Y. Investigation of the effect of installing guides in the pneumatic separation channel on the performance of a hammer crusher. In Proceedings of the XVIII all-Russian Scientific and Practical Conference, St. Petersburg, Russia, 20-21 November 2019; Volume 3, pp. 1015-1021.

10. Arkhipov, V.A.; Konovalenko, A.I. Practicum on the theory of similarity and the analysis of dimensions. In Educational and Methodological Guide; Tomsk State University: Tomsk, Russia, 2016; p. 92.

11. Ivanov, I.E.; Ereshchenko, V.E. Methods of Similarity of Physical Processes; MADI: Moscow, Russia, $2015 ;$ p. 144.

12. Westine, P.S.; Dodge, F.T.; Baker, W.E. Similarity Methods in Engineering Dynamics: Theory and Practice of Scale Modeling; Elsevier: Amsterdam, The Netherlands, 2012.

13. Palitsyn, A.V.; Ivanov, I.I. Development and Search Results of Research of a Rotary-Centrifugal Type Feed Grain Shredder for Farms. In Proceedings of the Current Issues of Improving the Technology of Production and Processing of Agricultural Products: Maslovskie Readings: Materials of International Scientific-Practical Conference, Yoshkar-Ola, Russia, 23-24 March 2017; pp. 284-289.

14. Gabryszuk, M.; Barszczewski, J.; Kuźnicka, E.; Sakowski, T. Effect of long-term fertilization of the permanent dry meadow on the zinc content in soil and meadow sward. J. Water Land Dev. 2020, X-XII, 61-65. [CrossRef]

15. Savinykh, P.A.; Isupov, A.Y.; Kuznetsov, N.N.; Ivanov, I.I. Assessment of the influence of various modes of operation of a rotary-centrifugal type grain shredder on the quality of the resulting product. In Energy-Saving Agricultural Technologies and Equipment for Northern Agriculture and Animal Husbandry: Monograph; Sysuev, V.A., Ed.; OOO "Kirov Regional Printing House": Kirov, Russia, 2018; pp. 269-274.

16. Ivanov, I.I.; Palitsyn, A.V.; Savinykh, P.A.; Isupov, A.Y. Results of practical research of experimental feed grain shredder of rotary-centrifugal type. In Problems of Intensification of Animal Husbandry Taking into Account Environmental Protection and Production of Alternative Energy Sources; Romaniuk, V., Ed.; Monograph under the Scientific; Publishing ITP: Falenty-Warsaw, Poland, 2018; pp. 55-60.

17. Savinykh, P.A.; Isupov, A.Y.; Ivanov, I.I. Results of research of a centrifugal-rotary grain shredder. Bull. NGIEI $2019,8,18-33$.

18. Savinykh, P.A.; Saitov, V.E.; Sukhlyaev, V.A.; Ivanov, I.I.; Palitsyn, A.V.; Kuznetsov, N.N. Device for Crushing Bulk Materials. Russian Patent Application Submitted 17 October 2016. Obtained Russian Patent No. 2656619, 6 June 2018.

19. Shagdyrov, I.B. Substantiation of Parameters of a Multistage Feed Grain Crusher. Ph.D. Thesis, Dis. Cand. Chelyabinsk Insitute of Agricultural Mechanization and Electrification, Chelyabinsk, Russia, 1988; p. 220.

20. Salman, A.D.; Ghadiri, M.; Hounslow, M. Particle Breakdown; Elsevier: Amsterdam, The Netherlands, 2007.

21. Melnikov, S.V.; Aleshkin, V.R.; Roshchin, P.M. Planning an Experiment in Research of Agricultural Processes; Kolos: Leningrad, Russia, 1980; p. 168.

22. Johnson, N.; Lyon, F. Statistics and Experiment Planning in Engineering and Science: Methods of Experiment Planning; Mir: Moscow, Russia, 1981; p. 520.

23. Herrera-Barros, A.; Tejada-Tovar, C.; Gonzalez-Delgado, A.D. Comparative assessment of Al2O3-modified biomasses from agricultural residues for nickel and cadmium removal. J. Water Land Dev. 2021, IV-VI, 29-34. [CrossRef]

24. Roman, K.; Roman, M.; Szadkowska, D.; Szadkowski, J.; Grzegorzewska, E. Evaluation of Physical and Chemical Parameters According to Energetic Willow (Salix viminalis L.) Cultivation. Energies 2021, 14, 2968. [CrossRef]

25. Roman, M.; Roman, K. Innowacyjne Wykorzystanie Biomasy Stałej w Gospodarstwach Agroturystycznych, Innovative Use of Solid Biomass in Agritourism Farms, Studia KPZK; Polska Akademia Nauk Komitet Przestrzennego Zagospodarowania Kraju: Warszawa, Poland, 2016; pp. 33-40.

26. Roman, K.; Barwicki, J.; Hryniewicz, M.; Szadkowska, D.; Szadkowski, J. Production of Electricity and Heat from Biomass Wastes Using a Converted Aircraft Turbine AI-20. Processes 2021, 9, 364. [CrossRef] 